\title{
ASPECTOS VIVENCIADOS NO ESTÁGIO CURRICULAR SUPERVISIONADO DO CURSO DE PEDAGOGIA DA UNEMAT, CÂMPUS DE JUARA
}

\author{
ASPECTOS EXPERIMENTADOS EN EL PRÁCTICA SUPERVISADA EN EL \\ CURSO DE LA PEDAGOGÍA UNEMAT, JUARA DE CÂMPUS
}

\author{
EXPERIENCED ASPECTS OF THE INTERNSHIP SUPERVISED OF THE \\ FACULTY OF EDUCATION OF UNEMAT
}

\author{
Ângela Rita Christofolo de MELLO. ${ }^{1}$ \\ Cleuza Regina Balan TABORDA. ${ }^{2}$
}

RESUMO: Este artigo socializa aspectos vivenciados enquanto professoras do Estágio Curricular Supervisionado do Ensino Fundamental III e IV, realizados pelos acadêmicos matriculados na V e VI fases do curso de Pedagogia, ofertado pela Universidade do Estado de Mato Grosso, câmpus de Juara. A investigação empírica, de abordagem qualitativa, analisou informações contidas nos relatórios elaborados pelos acadêmicos, como também coletadas no decorrer do acompanhemnto in loco. Conclui-se que o desenvolvimento do estágio nos moldes estabelecidos pela nova Matriz Curricular do referido curso, contribuiu com a formação dos pedagogos ao oportunizar a construção da práxis pedagógica, por meio da aproximação e da reaproximação destes junto às escolas.

PALAVRAS-CHAVE: Estágio Curricular. Pedagogia. Ensino Fundamental.

RESUMEN: En este artículo se socializa aspectos maestros experimentados como el supervisada de Educación Primaria III y IV, desarrollado por los estudiantes matriculados en la quinta y sexta etapas del curso pedagogía, ofrecido por la Universidad del Estado de Mato Grosso, Juara câmpus. La investigación empírica, enfoque cualitativo, examinó la información contenida en los informes construidos por académicos y recogidos durante acompanhemnto punto. Se concluye que la etapa de desarrollo en la forma establecida por la nueva Matriz Curricular de ese supuesto, contribuyó a la formación de los profesores, para crear oportunidades para la construcción de la praxis pedagógica, a través de la aproximación y el acercamiento de éstas, en las escuelas.

PALAVRAS CLAVE: Etapa Curricular. Pedagogía. Enseñanza Fundamental.

ABSTRACT: This article socializes aspects experienced while teachers of Curricular Internship Supervised of Education Basic III and IV, developed by students enrolled in the fifth and sixth phases of the Faculty of Education, offered by the University of the State of Mato Grosso, câmpus of Juara. The empirical research, qualitative approach, examined information contained in the reports constructed by academics and collected during accompaniment spot.

\footnotetext{
${ }^{1}$ Professora Adjunta da Universidade do Estado de Mato Grosso (UNEMAT), Faculdade de Educação e Ciências Sociais Aplicadas, câmpus de Juara/MT. Professora permanente do Programa de Pós-graduação Stricto Sensu, Mestrado Profissional em Letras (PROFLETRAS) da UNEMAT, câmpus de Sinop. Líder do Grupo de Estudo e Pesquisa de Formação Docente, Gestão e Práticas Educacionais (GEFOPE/UNEMAT), certificado pelo CNPq. Email: ritamello5@yahoo.com.br

${ }^{2}$ Professora assistente da UNEMAT, mestre em Educação pela Universidade Federal de Mato Grosso (UFMT), câmpus de Cuiabá, pesquisadora associada aos grupos de pesquisa: GRAFITE/UNEMAT e GEFOPE/UNEMAT, certificados pelo CNPq. Email: cleuregina@ hotmail.com
} 
Concluded that the development of internship as laid down by the the new curriculum, contributed to the training of educators, to create opportunities for construction of pedagogical praxis, through the approximation and of rapprochement of these, in the schools.

KEYWORDS: Curriculum Stage. Pedagogy. Elementary School.

\title{
Introdução
}

De acordo com o histórico do Projeto Político Pedagógico (PPP) do curso de Pedagogia, a Universidade do Estado de Mato Grosso (UNEMAT), instalou-se no município de Juara no ano de 2001 com a implantação do Núcleo Pedagógico de Juara. Este núcleo foi criado a partir da expansão do Campus de Sinop, para atender à demanda de formação superior na região do Vale do Arinos e ofertou cinco turmas especiais: uma de letras, duas de Ciências Contábeis e duas de Administração.

No ano de 2003, na primeira sessão ordinária do Conselho Superior Universitário (CONSUNI), por meio da Resolução nº 014/2003 foi aprovada a criação do Campus Universitário de Juara. Esta representou a democratização do Ensino Superior a uma parcela da população que em outra situação teria poucas oportunidades de cursá-lo (UNEMAT, 2007). Em conformidade com o PPP do referido curso:

\begin{abstract}
A implantação do Câmpus da UNEMAT em Juara sinalizou o comprometimento da Universidade do Estado de Mato Grosso frente às exigências de democratização do Ensino Superior, imprimindo alternativas de viabilização de projetos de ensino, de extensão e de produção científica, que podem fomentar o espírito crítico-reflexivo, proporcionando a valorização da cidadania, a identificação dos problemas socioeconômicos da região e a criação de alternativas de superação para os mesmos. (UNEMAT, 2007, p. 21).
\end{abstract}

A criação do Campus Universitário de Juara sinalizava a possibilidade da oferta de dois cursos regulares: Licenciatura Plena em Pedagogia e Bacharelado em Administração. Nestes termos, em 24 de outubro de 2003, o Conselho de Ensino, Pesquisa e Extensão por meio da Resolução no 240/2003/CONEPE, aprovou o PPP do Curso de Licenciatura Plena em Pedagogia do Campus Universitário de Juara, com o ingresso semestral de 40 acadêmicos. Porém, as atividades do curso de Pedagogia no Campus Universitário de Juara iniciaram-se em 25 de agosto de 2004. O seu reconhecimento pelo Conselho Estadual de Educação se deu por meio da Portaria $\mathrm{n}^{\circ}$ $173 / 2008$ de 01 de julho de 2008. Este reconhecimento foi aditado pelo Parecer $\mathrm{n}^{\mathrm{o}}$ 056/2010 de 22 de junho de 2010 (UNEMAT, 2013). Porém, o curso de Bacharelado 
em Administração foi implantado somente no primeiro semestre de 2012, com o ingresso semestral de 40 alunos.

Para atender aos objetivos e às determinações legais o PPP do curso de Pedagogia passou por algumas reestruturações. As primeiras adequações ocorreram por meio das resoluções nº 094/2005 e no 173/2006 do Conselho de Ensino, Pesquisa e Extensão (CONEPE). No ano de 2007, por meio da Resolução $n^{\circ} 116 / 2007$ foi aprovada a reestruturação do PPP do Curso de Pedagogia. Em 2013 a Proposta Pedagógica Curricular do Curso de Pedagogia foi novamente reestruturada. Com essas reestruturações, o Estágio Curricular Supervisionado sofreu alterações em relação à carga horária e a dinâmica de oferta (UNEMAT, 2013).

\section{O Estágio Curricular Supervisionado nas Matrizes Curriculares do Curso de Pedagogia, Campus de Juara}

O curso de Pedagogia da UNEMAT, campus de Juara, no período de 2004 a 2007 foi orientado pela Matriz Curricular $\mathrm{n}^{\circ} 112$, que estabelecia uma carga horária de 405 horas para os Estágios Curriculares Supervisionados que aconteciam durante o sétimo e oitavo semestres, assim distribuídas: 195 horas na Educação Infantil no $7^{\circ}$ semestre, e 210 horas no Ensino Fundamental no $8^{\circ}$ semestre. Em conformidade com o PPP do curso, os momentos de realização dos estágios exigiam atividades integralizadoras de acompanhamentos e supervisões com vistas a uma participação efetiva dos acadêmicos nas diferentes áreas de estudos, ao longo do curso.

A opção político-pedagógica encontrava-se fundamentada no processo de interação entre as modalidades da Educação Infantil, anos iniciais do Ensino Fundamental e Educação de Jovens e Adultos. Essa estrutura possibilitava o acesso dos acadêmicos às diferentes especificidades da formação de professor (UNEMAT, 2003). Todavia, a oferta dos Estágios Curriculares Supervisionados apenas nos últimos anos do curso, pode ser assim avaliada:

O Estágio Supervisionado da habilitação Magistério dos cursos de Pedagogia já é, por si só, um desafio. Desenvolvido, em geral, apenas no final do curso e, muitas vezes desvinculado das atividades praticadas pelos alunos nos semestres anteriores, o Estágio Supervisionado traz em si uma expectativa de apoteose, de grau finale, no qual todos os problemas e deficiências apresentadas durante o curso tem uma última chance de ser pelo menos discutidos. (KENSKI, 2004, p. 39-40). 
Entretanto, a orientação é de que os estágios não sejam desvencilhados das atividades de práticas pedagógicas trabalhadas no decorrer do curso, nem entendidos como elemento que irá solucionar todas as mazelas da trajetória vivenciada pelo acadêmico no decorrer do curso. Nestes termos, o desenvolvimento destas ações deve ser orientado por procedimentos e estratégias que visem o melhor aproveitamento dos momentos destinados à disciplina.

A reestruturação do curso de Pedagogia ocorrida por meio da Resolução $n^{\circ}$ 116/2007 se deu diante da necessidade de atender as exigências estabelecidas nas Diretrizes Curriculares Nacionais para o Curso de Graduação em Pedagogia (Resolução $\mathrm{CNE} / \mathrm{CP}, \mathrm{n}^{\circ}$ 1, de 15 de maio de 2006), que instituiu a formação em Pedagogia como um processo de construção de identidade do educador ativo, crítico e reflexivo (UNEMAT, 2013).

Em conformidade com essas Diretrizes, o Estágio Curricular Supervisionado deveria ser realizado ao longo do curso, de modo a assegurar aos graduandos experiência de exercício profissional, em ambientes escolares e não escolares, que ampliassem e fortalecessem atitudes éticas, conhecimentos e competências, prioritariamente na Educação Infantil e anos iniciais do Ensino Fundamental; nas disciplinas pedagógicas dos cursos de Ensino Médio, na modalidade Normal; na Educação Profissional; na área de serviços e de apoio escolar; na Educação de Jovens e Adultos; na participação em atividades da gestão de processos educativos, no planejamento, implementação, coordenação, acompanhamento e avaliação de atividades e projetos educativos; em reuniões de formação pedagógica (BRASIL, 2006), ou seja, em suas possíveis áreas de atuação.

Assim, a partir da reestruturação ocorrida em 2007, no curso de Pedagogia ofertado pela UNEMAT no Campus de Juara, entrou em vigor a Matriz Curricular $\mathrm{n}^{\circ}$ 054. Nesta Matriz o Estágio Curricular Supervisionado passou a acontecer no decorrer do curso com a intenção de garantir aos acadêmicos a atuação pedagógica nos contextos escolares e não escolares. A carga horária destinada aos Estágios passou a ser de 330 horas nas seguintes modalidades: 120 horas na Educação Infantil; 120 horas nos anos iniciais do Ensino Fundamental ou na Educação de Jovens e Adultos e 90 horas em Gestão Educacional.

O Estágio Curricular Supervisionado em Gestão acontecia no segundo, quinto e sétimo semestres e os acadêmicos poderiam escolher entre as diversas modalidades, tais 
como: direção e/ou administração escolar, coordenação pedagógica em ambientes escolares e não escolares. O Estágio Curricular Supervisionado em Educação Infantil acontecia no terceiro, quarto, quinto e sétimo semestres. Sendo que o terceiro semestre era destinado à observação e nos demais semestres aconteciam a docência supervisionada. No Ensino Fundamental, o estágio de observação acontecia no $3^{\circ}$ semestre, e o supervisionado, de iniciação à docência, aconteciam no sexto, sétimo e oitavo semestres, incluindo também a modalidade da Educação de Adultos.

Estas disciplinas contavam com uma carga horária de 30 horas, e a observação das práticas pedagógicas, tanto na Educação Infantil, como no Ensino Fundamental, se dava apenas no terceiro semestre (UNEMAT, 2007). Situação bastante criticada pela comunidade acadêmica, uma vez que o estágio de observação ocorria no terceiro semestre e nas demais etapas os acadêmicos realizavam as intervenções pedagógicas sem, em muitos casos, conhecer a realidade da turma na qual iria realizar as atividades de iniciação à docência.

Todavia, o Estágio Curricular Supervisionado abarca um conjunto de atividades que o acadêmico deverá desenvolver no decorrer do curso de formação. Nestes termos:

\begin{abstract}
O estágio é um componente do currículo que não se configura em uma disciplina, mas como uma atividade [...] propiciadora da inserção dos alunos nas instituições escolares - para conhecimento de como o processo de ensino aí se dá [...] esse conhecimento não se restringe a uma unidade escolar. Trata-se de tomar a unidade para compreendê-la na totalidade. [...] Da mesma forma o estágio pode servir as demais disciplinas e, nesse sentido, ser uma atividade articuladora do curso. E, como todas as disciplinas, é uma atividade teórica (de conhecimento e estabelecimento de finalidades) na formação do professor. Instrumentalizadora da práxis (atividade teórica e prática) educacional. De transformação da realidade existente. (PIMENTA, 2002, p. 121).
\end{abstract}

Neste sentido, a última reestruturação na Proposta Pedagógica Curricular do curso de Pedagogia ofertado pela UNEMAT no Campus Universitário de Juara se deu em atendimento à Normativa no 004/2011-UNEMAT, que estabelecia "os procedimentos de migração e revisão das matrizes curriculares dos cursos de graduação ofertados pela UNEMAT para a implantação do sistema de crédito em todas as suas modalidades [...]" a fim de promover a equivalência, parametrização e mobilidade acadêmica (UNEMAT, 2013).

A partir dessa reestruturação, o Estágio Curricular Supervisionado passou a contar com uma carga horária de 480 horas. Sendo 180 horas na Educação Infantil (90 
horas em creches e 90 horas na Pré-escola); 180 horas nos anos iniciais do Ensino Fundamental ( 90 horas no $1^{\circ}, 2^{\circ}$ ou $3^{\circ}$ anos e 90 horas no $4^{\circ}$ ou $5^{\circ}$ anos), 60 horas na Educação de Jovens e Adultos ( $1^{\circ}$ segmento) e 60 horas em Ambientes não Escolares (UNEMAT, 2013).

Nestes termos, na atual Matriz Curricular $\mathrm{n}^{\circ}$ 058, a organização e o desenvolvimento do estágio, nas diferentes etapas e modalidades, conta com uma carga horária destinada à observação e outra à iniciação a docência. Essa organização visa possibilitar ao acadêmico o acesso ao conhecimento da realidade educacional para compreender a função social da escola, desenvolver atividades vinculadas às funções do pedagogo em ambientes escolares e não escolares, promover a articulação entre a realidade vivenciada nestes espaços, com a teoria estudada no decorrer do curso, e vivenciar a prática pedagógica destas modalidades de ensino em todas as suas dimensões (UNEMAT, 2013).

\section{A Matriz Curricular $\mathbf{n}^{0} \mathbf{0 5 8}$ e $\quad$ o Estágio Curricular Supervisionado: encaminhamentos metodológicos de uma experiência em processo construtivo}

As informações sistematizadas e analisadas neste artigo provêm do trabalho realizado enquanto professoras da Universidade do Estado de Mato Grosso, Faculdade de Educação e Ciências Sociais Aplicadas, Departamento de Pedagogia, campus de Juara, no primeiro semestre de 2015, ocasião em que trabalhamos com duas disciplinas, assim denominadas: Estágio Curricular Supervisionado III no Ensino Fundamental (Observação/Iniciação à Docência na Alfabetização: $1^{\circ}, 2^{\circ}$ e $3^{\circ}$ anos) com os acadêmicos da quinta fase formativa, e Estágio Curricular Supervisionado IV no Ensino Fundamental (Observação e Iniciação à Docência: $4^{\circ}$ e $5^{\circ}$ anos) com os acadêmicos da sexta fase formativa, ambas com 90 horas.

As disciplinas foram ministradas com 58 alunos matriculados, desses 32 na $\mathrm{V}$ e 26 na VI fases, e as respectivas cargas horárias, assim distribuídas: 50 horas reservadas para o momento presencial na UNEMAT, que incluiu diversas atividades: discussões teóricas, legais e práticas com estudos dirigidos voltados para as atuais Orientações e Diretrizes Curriculares Nacionais e Estaduais, legislação que regulamenta estas atividades na Instituição, elaboração dos planejamentos, avaliações e construções de relatórios; 40 horas destinadas para o trabalho de campo, ou seja, para a realização dos dois momentos dos estágios nas escolas. 
Portanto, o trabalho desenvolvido nestas disciplinas abarcou distintos momentos e diversas atividades que incluiu: visitas às Secretarias Municipais de Educação dos Municípios de Juara, Novo Horizonte do Norte e Porto dos Gaúchos, e às Assessorias Pedagógicas de Juara e Porto dos Gaúchos para divulgação dos estágios e suas propostas pedagógicas; visitas às escolas campo pertencentes aos referidos municípios para entrega de ofícios, apresentação dos acadêmicos e posteriores acompanhamentos; aulas teóricas e práticas na universidade, em três momentos distintos: momento inicial para apresentação da estruturação das disciplinas, estudos teóricos, metodológicos e práticos com planejamentos do primeiro momento de intervenção docente (observação/participação); segundo momento com socializações das experiências vivenciadas no período de observação/participação, estudos e planejamentos das intervenções de iniciação a docência; terceiro momento para a socialização das experiências vivenciadas durante as intervenções docentes, auto avaliação e avaliação de todas as atividades realizadas durante o desenvolvimento das referidas disciplinas de Estágios.

Este trabalho resultou na elaboração de 29 planejamentos de observação/participação e 29 planejamentos de iniciação a docência ${ }^{3}$, construção de 58 fichas avaliativas e de 58 relatórios que apresentaram informações, reflexões e análises do trabalho efetivado pelos acadêmicos regularmente matriculados nas referidas disciplinas ${ }^{4}$. Alguns excertos contidos nestes documentos encontram-se sistematizados e analisados no item 3.3 deste artigo.

Consideramos estes dados empíricos por que foram coletados por meio de processos interativos, vivenciados por nós professoras supervisoras dos estágios e pelos acadêmicos no decorrer do primeiro semestre de 2015 no mesmo campo de atuação, ou seja, na realização de todas as ações concernentes aos Estágios Curriculares Supervisionados nos anos iniciais do Ensino Fundamental. Assim como nós, os acadêmicos estavam imersos neste espaço social, participaram das aulas presenciais na UNEMAT, observaram a escola campo e a sala de aula, auxiliaram o professor regente, planejaram e desenvolveram as intervenções pedagógicas e avaliaram todas as ações realizadas.

\footnotetext{
${ }^{3}$ Os dois momentos do Estágio foram realizados em duplas, assim como os planejamentos, que foram construídos pelas respectivas duplas de estagiários, tanto da V, como da VI fases formativas.

4 As fichas avaliativas e os relatórios críticos/reflexivos e fundamentados foram construídos individualmente pelos acadêmicos.
} 
Vale ressaltar que apesar de trabalharmos com informações contidas nos documentos construídos pelos acadêmicos, enquanto pesquisadoras e professoras da formação inicial de professores do curso de Pedagogia, ministrantes das referidas disciplinas, no decorrer do primeiro semestre de 2015, estivemos inseridas no espaço social analisado e atuamos de forma direta com as pessoas que contribuíram com esta investigação.

Desse modo, os excertos analisados resultam de um processo de coleta de informações interativas, a partir da realidade observada por meio do contato direto entre os sujeitos. Este implicou em integração à realidade observada, observação, participação, interação e diálogo com as pessoas envolvidas no processo investigativo. Portanto, a pesquisa de abordagem qualitativa, se valeu destes instrumentos. Segundo André (1995), neste tipo de investigação científica, as análises das informações empíricas são o principal foco de atenção dos pesquisadores, aspecto que exige aproximação e interação destes com o objeto em questão.

\title{
O Estágio Curricular Supervisionado no Curso de Pedagogia: aspectos de uma experiência em construção
}

De acordo com a ementa da disciplina de Estágio Curricular Supervisionado III no Ensino Fundamental (observação/intervenção na Alfabetização: $1^{\circ}, 2^{\circ}$ e $3^{\circ}$ anos), os acadêmicos matriculados na $\mathrm{V}$ fase formativa deverão realizar atividades voltadas para:

\begin{abstract}
Abordagem teórica relativa aos processos de ensino, aprendizagem, execução de atividade docente diretamente numa escola-campo de Ensino Fundamental - anos iniciais (com ênfase na alfabetização), com o desenvolvimento das etapas de observação, participação/monitoria, planejamento e desenvolvimento de um projeto pedagógico por meio da iniciação à docência, que proporcione ao estagiário o aprender a ser professor numa situação real de trabalho pedagógico. Nesse momento do Estágio Supervisionado nos anos iniciais do Ensino Fundamental os estagiários farão ainda, coleta de informações sobre a escola: alunos, professores, pais, aspectos físicos, administrativos e político-pedagógicos. (UNEMAT, 2013, p. 67).
\end{abstract}

Em relação à ementa da disciplina de Estágio Curricular Supervisionado IV no Ensino Fundamental (observação e iniciação à docência: $4^{\circ}$ e $5^{\circ}$ anos), as atividades realizadas pelos estagiários estão assim recomendadas: 


\begin{abstract}
Abordagem teórica relativa aos processos de ensino, de aprendizagem, execução de atividades docentes diretamente numa escola-campo de Ensino Fundamental - anos iniciais (com ênfase nos últimos anos). Desenvolvimento das etapas de observação, participação/monitoria, planejamento e realização do projeto pedagógico por meio da iniciação à docência, que proporcione ao estagiário o aprender a ser professor numa situação real de trabalho pedagógico. Os estagiários farão, ainda, coleta de informações sobre a instituição: crianças, professores, pais, aspectos físicos, administrativos e políticopedagógicos. (UNEMAT, 2013, p. 73-74).
\end{abstract}

Desse modo, o Estágio Curricular Supervisionado III no Ensino Fundamental (observação/intervenção na Alfabetização: $1^{\circ}, 2^{\circ}$ e $3^{\circ}$ anos) e o Estágio Curricular Supervisionado IV no Ensino Fundamental (observação e iniciação à docência: $4^{\circ}$ e $5^{\circ}$ anos), integram-se às atividades teóricas e práticas vivenciadas pelo acadêmico durante a realização do curso de Pedagogia. Estes deverão aproximar o futuro pedagogo do contexto escolar e o colocar em observação direta com um dos seus campos de atuação. Esta aproximação busca viabilizar a articulação entre os fundamentos teóricos das ciências humanas e do desenvolvimento humano estudados no decorrer do curso à prática docente desenvolvida no interior das salas de aulas.

Com esta articulação, o estágio visa propiciar a construção de conhecimentos necessários à atuação do pedagogo na docência, os quais incluem: diretrizes e orientações curriculares, planejamento educacional, elaboração de projetos de intervenções, sequências didáticas e de atividades, planos de aulas, recursos e estratégias de ensino, intervenções práticas e avaliações voltadas aos anos iniciais do Ensino Fundamental. Desse modo, os conhecimentos construídos durante a realização do estágio articular-se-ão e fundamentar-se-ão aos conceitos teóricos, metodológicos e práticos que constituem a formação do pedagogo. Esta dinâmica de atividades é necessária por que:

O exercício da atividade docente requer preparo. Preparo que não se esgota nos cursos de formação, mas para o qual o curso pode ser uma contribuição específica enquanto conhecimento sistemático da realidade do ensino-aprendizagem na sociedade historicamente situada, enquanto possibilidade de antever a realidade que se quer (estabelecimento de finalidades, direção de sentido), enquanto identificação e criação das condições técnico-instrumentais propiciadoras da efetivação da realidade que se quer. Enfim, enquanto formação teórica (onde a unidade teoria e prática é fundamental) para a práxis transformadora. (PIMENTA, 2002, p. 105). 
Pautadas nestes fundamentos, trabalhamos as consecutivas disciplinas com o objetivo de inserir o acadêmico na realidade educacional, especificamente na docência dos anos iniciais do Ensino Fundamental, com vistas a uma observação e uma intervenção pedagógica reflexiva em atenção aos estágios de desenvolvimento humano e aos conceitos relacionados às áreas de Linguagem, Ciências da Natureza, Ciências Humanas e Matemática e suas tecnologias, específicas desta etapa da escolarização básica.

Para tanto, propusemos atividades que permitiram analisar as Diretrizes e as Orientações Curriculares para o Ensino Fundamental e os Projetos Políticos Pedagógicos das escolas campo. Observar a dinâmica de funcionamento das escolas campo com atenção ao calendário letivo, a organização do espaço tempo, aos princípios da gestão democrática, ao planejamento, a intervenção e a avaliação das turmas. Investigar o perfil dos alunos da turma em que realizariam a intervenção e diagnosticar se havia aluno com deficiência ou com problemas de aprendizagem. Observar a rotina adota pelo professor no interior da sala de aula, ou seja, como ele desenvolvia a aula, quais materiais didáticos, recursos e estratégias de ensino utilizava, se havia alunos que frequentavam a sala de articulação e como acontecia a articulação entre o professor da sala e o professor articulador. Verificar como acontecia a relação professor/aluno, aluno/aluno, direção/coordenação/professores/ aluno e família. Elaborar projetos de intervenções, sequências didáticas ou de atividades e/ou planos de aula ${ }^{5}$. Realizar a intervenção pedagógica em turmas dos anos iniciais do Ensino Fundamental. Construir relatório crítico e reflexivo, fundamentado nos aportes teóricos estudados no curso.

Resumidamente, seguimos estas estratégias para trabalhar as referidas disciplinas. No primeiro momento, trabalhamos a Resolução no . 029/2012/CONEP que regulamenta a realização do Estágio Curricular Supervisionado nos cursos de licenciatura da UNEMAT. Em seguida, apresentamos o nosso plano de ensino com pontuações dialogadas e fundamentadas. Dando continuidade, trabalhamos os fundamentos das Diretrizes Curriculares Nacionais e das Orientações Curriculares de Mato Grosso para a Educação Básica/Ensino Fundamental. Utilizamos leitura e exposições interativas.

5 Trabalhamos alguns aspectos destes planejamentos durante a parte presencial na Universidade e os acadêmicos tiveram autonomia para escolher o que melhor atenderia a rotina/realidade da sala de aula em que realizariam a intervenção pedagógica. Aproximadamente 50\% das duplas optaram por sequências de atividades, por ser o planejamento habitualmente utilizado por boa parte das professoras regentes das turmas. 
Por meio de aula dialogada, identificamos os conhecimentos dos acadêmicos acerca dos conteúdos curriculares correspondentes aos anos iniciais do Ensino Fundamental. Dando continuidade, disponibilizamos aos acadêmicos o quadro de escolas campo para a realização das 40 horas de Estágio, definimos as equipes e apresentamos os períodos de realização das atividades de observação/participação e de intervenção docente, em conformidade com o horário elaborado pela coordenação do curso de pedagogia. Construímos coletivamente o cronograma com todas as atividades que deveriam ser desenvolvidas no estágio, com 20 horas reservadas para observação e monitoria e 20 horas para a intervenção docente em salas de aulas dos anos iniciais do Ensino Fundamental.

Dando continuidade às atividades, elaboramos coletivamente um roteiro com os aspectos que os acadêmicos deveriam observar na etapa de observação, com especial atenção quanto: ao número de alunos matriculados e que frequentavam a turma; de alunos com alguma deficiência ou com problemas de aprendizagem; identificação das deficiências ou problemas de aprendizagem e como a professora planejava para trabalhar com estes alunos; quantos frequentavam a articulação, quantas vezes por semana, em qual horário, como a professora da turma e a professora articuladora "articulavam" as atividades realizadas com estes alunos; se havia na sala assistente para alunos com deficiência e como era a sua colaboração; como a professora planejava suas aulas, quais materiais (livros/apostilas), recursos e estratégias didáticas ela utilizava. Estes foram os aspectos observados pelos estagiários durante a realização da observação/participação.

Realizado o período de observação, com o nosso acompanhamento e orientação, os acadêmicos tiveram um espaço de tempo para elaboração dos projetos de intervenções, sequências didáticas ou de atividades, e/ou planos de aulas levando em conta a realidade observada e o planejamento anual elaborado pelos professores das turmas em que iriam realizar o estágio de intervenção. Com os planejamentos construídos e por nós corrigidos, os acadêmicos retornaram às escolas campo e realizaram 20 horas de intervenção docente na mesma sala de aula em que realizaram a observação, com o nosso acompanhamento. Estas atividades foram realizadas nas escolas públicas dos municípios de Juara, Novo Horizonte do Norte e Porto dos Gaúchos, que ofertavam os anos iniciais do Ensino Fundamental.

Ao término da intervenção pedagógica, os acadêmicos tiveram um momento destinado para elaborarem, com o nosso acompanhamento e orientação, o relatório 
reflexivo e socialização das experiências vivenciadas, pois de acordo com Pimenta (2002, p. 70), "a prática não se restringe ao fazer, ela se constitui numa atividade de reflexão que enriquece a teoria que lhe deu suporte. O estágio é um processo criador, de investigação, explicação, interpretação e intervenção na realidade".

Fundamentada nos conceitos de avaliação formativa, diagnóstica e processual, a avaliação dos acadêmicos teve como referência os seguintes critérios: compromisso e responsabilidade no desenvolvimento de todas as atividades voltadas a realização destes estágios, quais sejam: levantamento bibliográfico, leituras, fichamentos, seleção de materiais e de recursos didáticos, participação e interação em sala de aula com socialização das experiências vivenciadas nas escolas campo e demais etapas. Postura crítica e reflexiva no desenvolvimento das atividades e nos debates em sala de aula, com demonstração de domínio dos conceitos abordados, fundamentação teórica nas exposições orais e na elaboração do relatório, assiduidade e pontualidade na elaboração e entrega do roteiro de observação/participação em sala, da elaboração do projeto de intervenção, sequências didáticas ou de atividades e ou planos de aula, bem como do relatório crítico reflexivo, acompanhado da ficha avaliativa, devidamente assinada pelo diretor da escola. Ou seja, do compromisso e da seriedade do acadêmico na realização de todas as etapas concernentes à realização destas ações, como também, da autoavaliação que se configurou em um processo de reflexões dos conhecimentos construídos por meio das experiências vivenciadas.

\section{Apontamentos: a experiência vivenciada pelos acadêmicos durante a realização do Estágio Curricular Supervisionado nos anos iniciais do Ensino Fundamental}

A nova Matriz Curricular foi implantada no ano de 2014/1, na primeira fase formativa, e no ano de 2015 foi implantada da primeira às $6^{\text {a }}$ fases formativas na UNEMAT, campus de Juara. Esta Matriz trouxe inovações pedagógicas para o Estágio Curricular Supervisionado. De acordo com os depoimentos dos acadêmicos matriculados na V e na VI fases formativas do curso de pedagogia no semestre 2015/1, que realizaram os Estágios Curriculares Supervisionados nos anos iniciais do Ensino Fundamental, um dos aspectos relevantes destas inovações conferem ao acréscimo de 60 horas nos créditos destas disciplinas. A Matriz anterior ofertou os respectivos estágios divididos em 30 horas de atividades, distribuídas em quatros semestres $\left(3^{\circ}, 6^{\circ}\right.$, 
$7^{\circ}$ e $8^{\circ}$ ) para esta modalidade educativa. Condição que segundo os acadêmicos, fragmentava o processo. $\mathrm{O}$ excerto que segue, confirma o aspecto destacado:

O estágio realizado neste semestre nos proporcionou dois momentos de suma importância para nossa trajetória acadêmica e profissional. Um primeiro estágio de observação em uma referida escola, e o de intervenção na mesma escola. Ambos os estágios realizados no Ensino Fundamental [...]. Foi uma experiência muito importante observar a sala de aula em todos os aspectos, como a professora trabalhava com os alunos, a forma que eles se comportavam durante as aulas, a forma de aprendizado, a relação entre professor $\mathrm{x}$ alunos e vice-versa. Construir uma sequência didática para a uma semana de intervenção, e trabalhar com os alunos esta sequência foi muito gratificante. (Relatório Acadêmica 1, V fase, 2015).

Como evidencia o depoimento, a nova reconfiguração do estágio na Matriz Curricular $n^{\circ} 058$, possibilitou aos acadêmicos um maior envolvimento com as escolas campo. Estes relataram que os dois momentos de estágios qualificaram os processos porque tiveram a oportunidade de conhecer a organização da escola, da sala de aula em que realizariam a iniciação docente, bem como o perfil dos alunos.

Conhecer o perfil dos alunos é necessário e importante. Neste sentido, as orientações contidas nos Parâmetros Curriculares Nacionais destacam que:

\begin{abstract}
As necessidades cotidianas fazem com que os alunos desenvolvam uma inteligência essencialmente prática, que permite reconhecer problemas, buscar e selecionar informações, tomar decisões e, portanto, desenvolver uma ampla capacidade [...]. Quando essa capacidade é potencializada pela escola, a aprendizagem apresenta melhor resultado. (BRASIL, 2000, p. 37).
\end{abstract}

Nestes termos, esta Matriz Curricular atende às atuais orientações pedagógicas, ao considerar que "ser professor significa focalizar o aluno, criando situações favoráveis para aumentar as probabilidades de aprendizagens e utilizar métodos ativos de ensino para desenvolver os conhecimentos, as habilidades e as atitudes pretendidas" (VEIGA, 2004, p. 27). Assim, as 20 horas de observação/participação que antecederam ao segundo momento, o de intervenção pedagógica, foi fundamental por que permitiu aos acadêmicos conhecer o interior da sala de aula, os estudantes e o desdobramento das intervenções realizadas pelo professor regente.

Os relatórios construídos pelos acadêmicos apresentaram informações que destacam a relevância da realização dos Estágios Curriculares Supervisionados no curso 
de pedagogia. Os acadêmicos destacaram a importância deste contato com a realidade escolar, momento ímpar que oportunizou conhecer os problemas e os enfrentamentos da profissão, como demostra o depoimento:

Pela primeira vez senti na pele o que o professor passa. Há muito descaso com a Educação, e o professor acaba tendo que se virar com o que tem, que não é o suficiente para exercer sua profissão com dignidade e trabalhar com os alunos de maneira a alcançar seus objetivos (Relatório Acadêmica 2, VI fase, 2015/1).

Dentre as muitas contribuições provenientes da realização dos estágios destacadas pelos acadêmicos, incluiu-se a decisão para a permanência no curso, conforme afirmação que segue: “O estágio de observação e de regência nos dá a base, mostra a realidade e nos faz sentir na pele o que é ser professor e conviver com a realidade escolar. É nesse momento que se torna decisiva a escolha de ser professor ou não" (Relatório Acadêmica 3, V fase, 2015/1). Além disso,

O estágio contribuiu principalmente para minha formação, uma vez que pude conciliar a teoria e a prática, onde por uma semana tive a oportunidade de atuar como professora, podendo pôr em prática todas as aprendizagens até aqui adquiridas no curso e aprendendo ainda mais, construindo assim, mais conhecimento e experiência. (Acadêmica 4, $\mathrm{V}$ fase).

Um dos aspectos mais mencionado pelos acadêmicos nos relatórios analisados foi a relação teoria \& prática. A maioria dos acadêmicos afirmou que a realização destas atividades denotou o distanciamento entre os fundamentos teóricos e a realidade prática. No entanto, alguns depoimentos apontam a possibilidade de reflexão entre ambas, como um dos aspectos positivos propiciados pela sua realização:

O estágio, principalmente o de intervenção no Ensino Fundamental, é um momento que leva o acadêmico a refletir suas próprias ações dentro da sala de aula, pois é quando ele tem a oportunidade de estabelecer uma relação entre a teoria e a prática. O estágio de intervenção é visto também como período de exercício profissional, previsto em currículo, pois é o período em que o estudante de pedagogia encontra-se em contato direto com o ambiente de trabalho. (Relatório Acadêmica 5, VI fase, 2015/1).

Além do contato com a escola, professores e alunos, tivemos também a oportunidade de refletir sobre a articulação entre teoria e prática no processo educativo a partir da interação entre a reflexão adquirida no decorrer do curso de Licenciatura Plena em Pedagogia e a atuação em 
situações concretas da realidade escolar. (Relatório Acadêmica 6, V fase, 2015/1).

Como afirmamos, são muitas as contribuições contidas nos relatórios que reafirmam a importância dos estágios para o curso de Pedagogia. Estas confirmam que “o estágio é o eixo central na formação de professores, pois é através dele que o profissional conhece os aspectos indispensáveis para a formação da construção da identidade e dos saberes do dia-a-dia" (PIMENTA e LIMA, 2004). Desse modo, as disciplinas que ofertam os estágios precisam ser constantemente revistas e redimensionadas nos Projetos Políticos Pedagógicos dos cursos de Licenciaturas, com vistas a atender as expectativas dos acadêmicos e aos objetivos dos cursos, que não pode perder a sua dimensão didático-pedagógica, ou seja, formar professores para o efetivo exercício da docência.

\section{Considerações finais}

A realização dos Estágios Curriculares Supervisionados demanda trabalho cooperativo e esforços conjuntos entre as várias disciplinas do curso e as instâncias envolvidas com este processo. Atuar como professoras supervisoras destas disciplinas implica em experiência docente na modalidade supervisionada, compromisso e dedicação. São muitas as ações sob a responsabilidade de uma professora supervisora de estágio. Estas impõem intenso ritmo de trabalho em todos os momentos, tanto nos presenciais que acontecem na universidade, como nos vivenciados nas escolas campo.

São muitos os documentos que precisam ser elaborados com o acompanhamento e a observação do professor supervisor. A correção destes materiais demanda exaustivo tempo e dedicação que ultrapassam a carga horária de trabalho reservada às disciplinas.

Contudo, a experiência é gratificante por que possibilita muitas aprendizagens. A aproximação e a interação com todas as instâncias da Educação Básica, especialmente com as escolas, produz elementos importantes que provocam constantes reflexões entre a formação inicial ofertada pela a universidade e as atuais políticas públicas implementadas na Educação Básica, pelas instâncias governamentais.

Os relatórios construídos pelos acadêmicos são densos em dados empíricos que merecem ser analisados. Estes refletem a realidade da Educação Básica em nossa região 
e chamam a atenção para a necessidade de inovações pedagógicas que respondam ao perfil dos estudantes dos anos iniciais do Ensino Fundamental.

Dentre outras contribuições, estas atividades provocam, tanto em nós professoras, como nos acadêmicos estagiários, a esperança e o desejo de transformação social, como comprova o depoimento: "o contato com a realidade escolar permitiu ver que podemos tentar mudar a realidade, tanto da escola, como dos alunos, incentivandoos a buscar seus sonhos e nunca desistir de lutar pelos seus ideais" (Relatório Acadêmica 7, V fase, 2015/1). Esse desejo, que em alguns momentos se transforma em utopia, nos mobiliza a prosseguir com a luta em prol de uma educação pública democrática e de qualidade social para todos.

Esta é uma experiência em construção e acreditamos que gradativamente será reajustada para a melhoria do trabalho desenvolvido nos estágios da UNEMAT, curso de Pedagogia, campus de Juara. Em construção por que a Matriz Curricular e o PPP do curso de Pedagogia estão em constante análise. Estas provocam reconfigurações que, acreditamos, tendem a renovar e a adequar as práticas curriculares em atenção à formação de professores reflexivos, que buscam a partir da reflexão, inovar a sua atuação docente em prol dos anseios e das necessidades da sua demanda educativa.

\section{Referências}

ANDRÉ, Marli Eliza Dalmazo Afonso de. Etnografia da prática escolar. SP, Campinas: Papirus, 1995.

BRASIL MEC. Parâmetros Curriculares Nacionais: Matemática/Secretaria de Educação Fundamental. 2a ed. Rio de Janeiro: Dp\&a, 2000.

BRASIL, Resolução CNE/CP n ${ }^{\circ}$, de 15 de maio de 2006. Diretrizes Curriculares Nacionais para o Curso de Graduação em Pedagogia, licenciatura. Disponível em:

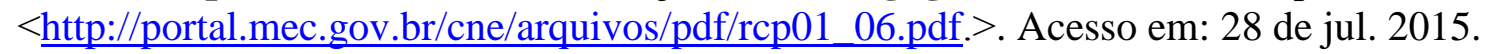

KENSKI, Vani Moreira. A vivência escolar dos estagiários e a prática de pesquisa em estágios supervisionados. In. FAZENDA, Ivani Catarina Arantes (et. al.) A Prática de Ensino e o Estágio Supervisionado. Campinas, SP: Papirus, 1991.

PIMENTA, Selma Garrido. O estágio na formação de professores: unidade teoria e prática? 5. ed. São Paulo: Cortez, 2002.

PIMENTA, Selma Garrido; LIMA, Maria Socorro Lucena. Estágio e Docência. São Paulo: Cortez, 2004. 
UNEMAT. UNIVERSIDADE DO ESTADO DE MATO GROSSO. Projeto Político Pedagógico do Curso de Pedagogia. Departamento de Pedagogia. Câmpus Universitário de Juara. 2003.

UNEMAT. UNIVERSIDADE DO ESTADO DE MATO GROSSO. Projeto Político Pedagógico do Curso de Pedagogia. Departamento de Pedagogia. Câmpus Universitário de Juara. 2007.

UNEMAT. UNIVERSIDADE DO ESTADO DE MATO GROSSO. Projeto Político Pedagógico Curricular do Curso de Pedagogia. Departamento de Pedagogia. Câmpus Universitário de Juara. 2014.

UNEMAT. UNIVERSIDADE DO ESTADO DE MATO GROSSO. Regulamento do Estágio Curricular Supervisionado dos Cursos de Graduação de Licenciatura da UNEMAT. RESOLUÇÃO No 028, de 03/06/2012.

VEIGA, Ilma Passos Alencastro. Repensando a didática. 24 ed. Campinas, SP: Papirus, 2004.

\section{Como referenciar este artigo}

MELLO, Ângela Rita Christofolo de; TABORDA, Cleuza Regina Balan. Aspectos vivenciados no estágio curricular supervisionado do curso de pedagogia da UNEMAT, Câmpus de Juara. Revista Ibero-Americana de Estudos em Educação, Araraquara, v.12, n.1, p. 134-150, 2017. Disponível em: <http://dx.doi.org/10.21723/riaee.v12.n1.8047>. E-ISSN: 1982-5587.

Data de submissão: jan/2016

Aprovação final: fev/17 